\title{
Cianobactérias, cianotoxinas e o tratamento químico da água: uma análise bibliométrica da produção científica mundial
}

\author{
Luciana Muller \\ ambiental.muller@gmail.com \\ Univerisdade Tecnológica Federal do \\ Paraná, Curitiba, Paraná, Brasil \\ Thomaz Aurélio Pagioro \\ thomazap@gmail.com \\ Univerisdade Tecnológica Federal do \\ Paraná, Curitiba, Paraná, Brasil \\ Adriane Martins de Freitas \\ afreitas.utfpr@gmail.com \\ Univerisdade Tecnológica Federal do \\ Paraná, Curitiba, Paraná, Brasil \\ Lucia Martins Pagioro \\ cmartins.utfpr@gmail.com \\ Univerisdade Tecnológica Federal do \\ Paraná, Curitiba, Paraná, Brasil
}

\begin{abstract}
RESUMO
Este trabalho apresenta o resultado de análise bibliométrica realizada com o intuito de analisar a produção científica mundial sobre cianobactérias, cianotoxinas e o tratamento químico de água.Devido à infinidade de técnicas e à grande diversidade de cianotoxinas identificadas atualmente, optou-se por restringir a análise das publicações, voltando-se para os métodos químicos de tratamento de água aplicados de maneira singular ou combinados, para degradação e remoção de cianotoxinas da água, focando principalmente nos casos práticos para remoção de MC-LR. Em um primeiro momento, procedeu-se a análise do perfil das publicações, identificando-se quais foram os periódicos mais utilizados para a divulgação das pesquisas, a procedência geográfica e institucional dos autores e da bibliografia utilizada, além da análise das citações e das redes de relações estabelecidas mundialmente, referentes às publicações científicas sobre cianobactérias, cianotoxinas e o tratamento de água. Em termos numéricos, analisaram-se os dados bibliométricos de 1255 trabalhos publicados entre 1980 e junho de 2017 . O ano de 2013 apresentou o maior número de publicações desde 1980.
\end{abstract}

PALAVRAS-CHAVE:Produção Científica. Cianobactérias. Água de Abastecimento. Tratamento de água. 


\section{INTRODUÇÃO}

As cianobactérias, anteriormente também chamadas de "algas azuis" (denominação antiga que caiu em desuso) compreendem um grupo de microrganismos procariontes, unicelulares ou multicelulares, que realizam fotossíntese aeróbia (CASTENHOLZ; WATERBURY, 1989). Apesar de sua fundamental importância na produção primária da cadeia trófica, da contribuição de espécies na fixação de nitrogênio para o solo, do seu potencial para produção de alimentos e geração de energia, as cianobactérias podem desencadear uma série de problemas. Cepas toxigênicas têm sido encontradas tanto em sistemas de águas interiores quanto em águas costeiras, no Brasil e no mundo. Em se tratando de água de abastecimento, o crescimento excessivo de cianobactérias em reservatórios gera problemas práticos graves (CHORUS; BARTRAN, 1999).

As cianotoxinas representam um desafio para o tratamento de água potável, uma vez que envolve a remoção de substâncias orgânicas na forma solúvel, e também presentes no interior das células. Há dois tipos de processos aplicados ao tratamento de água. Os processos de separação, onde geralmente são empregadas barreiras físicas, e os processos de conversão, que são de natureza química. Embora os processos de conversão sejam caracterizados por destruir a substância de interesse, poderá ocorrera formação de subprodutos da reação. Processos de conversão ideais são aqueles cujos produtos de reação são inócuos (HRUDEY et al., 1999).

De acordo com os mecanismos de toxicidade, os efeitos das cianotoxinas variam de hepatotóxicas, neurotóxicas e dermatotóxicas, podendo levar à inibição geral da síntese de proteínas. De acordo com a estrutura química, dividem-se em três grandes grupos: peptídeos cíclicos, alcalóides e lipopolissacarídeos (LPS). Como o próprio nome sugere, as hepatotoxinas atacam diretamente o fígado. As Microcistinas (MCs) compõem a classe de hepatotoxinasmais frequentemente encontrada ao nível global. Os efeitos observados variam de agudos a crônicos, dependendo das condições de exposição. Bioensaiosagudos em ratos demonstraram que estas cianotoxinas causam a morte por hemorragia hepática dentro de algumas horas. Efeitos crônicos estão relacionados ao surgimento de tumores (SIVONEN; JONES, 1999).

A partir da década de 1990, cianobactérias e cianotoxinas passaram a ganhar destaque no cenário mundial, devido aos crescentes casos de intoxicação envolvendo animais e humanos. Neste sentido, as análises da tendência das pesquisas acadêmicas sobre o tema tem sido premente e tem se tornado viável a partir das análises bibliométricas.

A bibliometria é um método quantitativo, a partir do qual é possível evidenciar as tendências da produção científica em determinado assunto, bem como as relações entre os grupos de pesquisas e de coautoria, a partir da análise de bases de dados. A diferença essencial entre otradicional levantamento bibliográficoe a bibliometria é que esta utiliza métodos quantitativos - a abordagem bibliométrica consiste na aplicação de técnicas estatísticas e matemáticas, na busca por uma avaliação objetiva da produção científica (NICHOLAS e RITCHIE, 1978).

A bibliometria abrange todos os estudos que procuram quantificar os processos da comunicação escrita, aplicando métodos numéricos específicos. 
Para Araújo (2006), a área mais importante da bibliometria é a análise de citações, que investiga as relações entre os documentos citantes e os documentos citados considerados como unidades de análise, no todo ou em suas diversas partes: autor, título, origem geográfica, ano e idioma de publicação.

O objetivo do trabalho foi compilar os principais autorese publicações a respeito de cianobactérias e cianotoxinas, obtendo-se o perfil da produção científica mundial,sob o ponto de vista de conteúdo e abordagens. Devido à infinidade de técnicas e à grande diversidade de cianotoxinas identificadas atualmente, optou-se por restringir a análise das publicações, voltando-se para os métodos químicos de tratamento de água aplicados de maneira singular ou combinados, para degradação e remoção de cianotoxinas da água, focando principalmente nos casos práticos para remoção de MC-LR.

\section{MATERIAIS E MÉTODOS}

Com a finalidade de obter-se um perfil das publicações, foram geradas as seguintes análises descritivas de frequência: distribuição das publicações dos artigos por ano e por autor, classificação das publicações por instituição de origem dos autores, distribuição das publicações por país de origem dos autores e distribuição das publicações por periódico.

Além disso, efetuaram-se a análise das citações e das networks estabelecidas mundialmente, referentes às pesquisas sobre cianobactérias, cianotoxinas e métodos de tratamento de água para retirada das mesmas. Em um segundo momento avaliaram-se os métodos de tratamento empregados, com destaque para os tratamentos químicos.

A base metodológica deste estudo foi a pesquisa bibliográfica apoiada na bibliometria, em que as principais etapas consistiam na:

a) Escolha da base de dados;

b) Definição das palavras-chave e formulação do stringde busca;

c) Análise das características das publicações;

d) Análise das referências que fundamentam as publicações;

e) Análise das principais publicações;

f) Análise geral das publicações;

\section{Seleção da base de dados}

A base de dados escolhida para esta pesquisa foi a Scopus, em função de sua abrangência e efetividade, principalmente no que tange os temas desta pesquisa.

\section{Processamento de dados}

Há diversos softwares comerciais e gratuitos de processamento de dados. Neste trabalho optou-se pela utilização dosoftware livre Bibexcel (desenvolvido na Universidade de Viena). 
Este software permitiu explorar o fluxo de interação e integração de conhecimentos da comunidade científica, através da análise das citações. Segundo Ruas e Pereira (2014), saber como trabalhos de um mesmo autor estão relacionados com as referências de outros trabalhos contemporâneos é uma informação interessante. A partir da informação do resumo, no Bibexcel foi possível relacionar como trabalhos altamente referenciados propiciam que novas ideias surjam.

\section{Mapeamento dos Resultados}

A interpretação dos padrões extraídos e processados no Bibexel se deu através do softwarelivrePajek (desenvolvido na Universidade de Ljubljana) que dispões de ferramentas estatísticas e de visualização que permitem fazer uma análise precisa dos resultados.

\section{Definição das Palavras-Chaves}

A definição das palavras-chave foi determinada a partir dos três enfoques relacionados ao tema de referência (as cianobactérias, as cianotoxinas, e a problemática envolvendo o tratamento da água de abastecimento público), dos termos em inglês e de termos similares ou sinônimos (Quadro 01).

O string de busca é formado pelo arranjo conveniente das palavras-chave com os operadores lógicos ANDe OR. Utilizou-se o conectivo "AND" para alcançar autores que tratassem do tema "técnicas de tratamento", e não apenas em aspectos biológicos ou de saúde. Devido à infinidade de técnicas e à grande diversidade de cianotoxinas identificadas atualmente, optou-se por restringir a análise das publicações, voltando-se para os métodos químicos de tratamento de água aplicados de maneira singular ou combinados, para degradação e remoção de cianotoxinas da água, focando principalmente nos casos práticos para remoção de MC-LR.

Quadro 01. Escolha das palavras-chave

\begin{tabular}{|c|c|c|}
\hline $\begin{array}{l}\text { Tema de } \\
\text { referência }\end{array}$ & $\begin{array}{l}\text { Termos em } \\
\text { inglês }\end{array}$ & Similares ou sinônimos de interesse \\
\hline Cianobactéria & Cyanobacteria & $\begin{array}{c}\text { "Cyanobacterial", "Cyanophyceae" "Cyanobacterial } \\
\text { blooms", "Blue-green algae", "Harmful } \\
\text { Cyanobacteria", "Photosynthetic Prokaryotes", } \\
\text { "Microcystisaeruginosa". }\end{array}$ \\
\hline Cianotoxinas & Cyanotoxins & "Hepatotoxins", "Microcistins", "Microcistin-LR". \\
\hline $\begin{array}{l}\text { Tratamento de } \\
\text { água }\end{array}$ & $\begin{array}{l}\text { Water } \\
\text { treatment }\end{array}$ & $\begin{array}{l}\text { "Water treatment", "Water supply", "Sanitation", } \\
\text { "Water Purification". }\end{array}$ \\
\hline
\end{tabular}

(Fonte: Autoria própria, 2017)

RESULTADOS

Formulação do String de busca 
O grupo de palavras-chave deu origem ao stringde busca, utilizado como ferramenta de investigação na base de dados Scopus(Quadro 02).

\begin{tabular}{l} 
Quadro 02. String de busca (Fonte: Autoria própria, 2017) \\
\hline (("Cyanobacteria" OR "Cyanobacterial" OR \\
"Cyanophyceae" OR "Cyanobacterial blooms" OR "Blue- \\
green algae" OR "Photosynthetic Prokaryotes" OR \\
"Harmful Cyanobacteria" OR "Microcystisaeruginosa") \\
AND ("Hepatotoxins" OR "Microcistins" OR "Microcistin- \\
$L R$ ") AND ("Water treatment" OR "Water supply" OR \\
"Sanitation" OR "Water Purification")).
\end{tabular}

Aplicadas as devidas limitações em relação às áreas de pesquisa compreendida pelo string de busca determinado, a busca inicial resultou em 1255 documentos, um número bastante significativo e que expressa a ênfase cientifica dos assuntos escolhidos. $\mathrm{O}$ ano com publicação mais antiga, dentro dos critérios estabelecidos foio de 1980, desta forma o período de tempo contemplado pelo estudo foi de 1980 a Junho de 2017.

\section{Análise das características das publicações}

Do total geral de publicações avaliadas, $77,9 \%$ correspondem a artigos emperiódicos, $13,2 \%$ são artigos de revisão, $4,1 \%$ são artigos publicados em congressos, $4,1 \%$ foram livros ou capítulos de livros, enquanto que as demais se referem a editoriais, cartas e short survey.

A Figura 01 compreende as 1255 publicações selecionadas, indicando um grande crescimento do número de publicações nas últimas duas décadas, no que se refere aos temas desta pesquisa. Observou-se que no ano de 1996 as publicações mais que dobraram com relação ao ano anterior (destaque da figura). Tal fato pode ser correlacionado ao maior caso comprovado de intoxicação humana por microcistinas, que aconteceu em Caruaru (Pernambuco) no ano de 1996, sendo que a partir deste ano estabeleceu-se um novo patamar de crescimento, sugerindo maior interesse pelo tema.

2013 foi o ano com o maior número de publicações desde 1980, com 93 publicações. 
Figura 01. Número de publicações por ano, sobre o tratamento de água com presença de cianobactérias e microcistinas, a partir do string de busca definido (Fonte: Scopus, 2017)

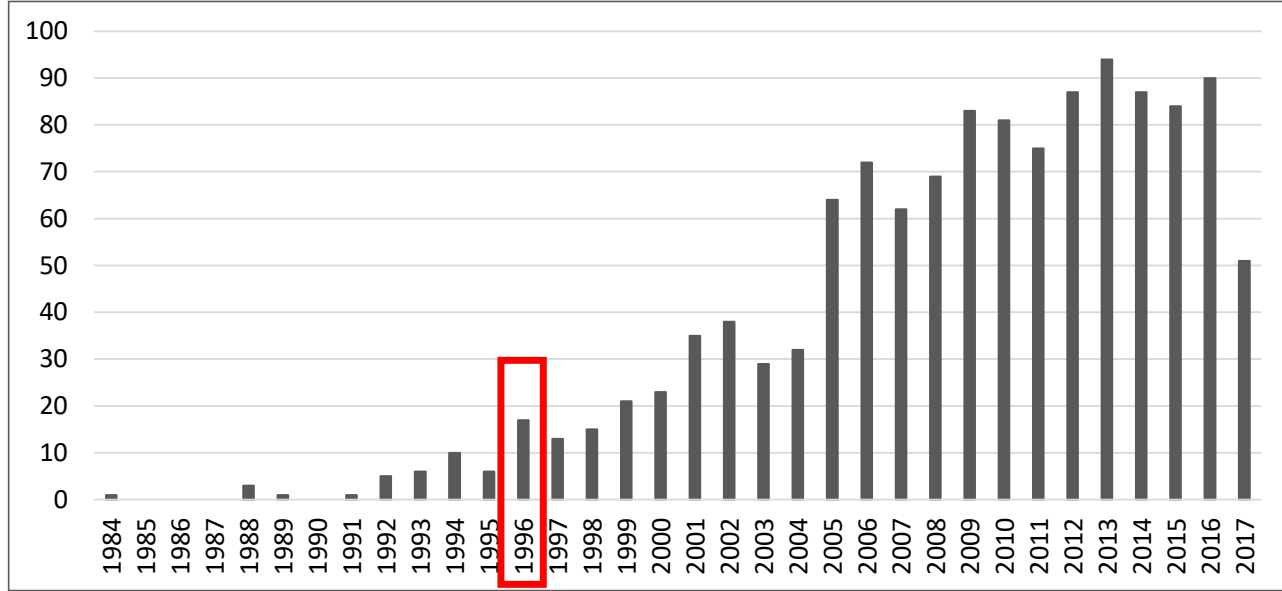

A amostra total foi constituída por 152 autores, sendo que estes têm no mínimo quatro publicações cada. Os vinte autores que mais se destacaram neste período em número de publicações estão representados na Figura 02.

O pesquisador Vitor Vasconcelos (Universidade do Porto - Portugal) apareceu em primeiro lugar. Este autor se destaca por suas pesquisas que tratam da presença de cepas tóxicas de cianobactérias em lagos de Portugal, implicações ecológicas, caracterização das cianotoxinas e dos seus efeitos sobre animais aquáticos, o risco para a saúde humana e o abastecimento público.

Figura 02. Autores com o maior número de publicações, em escala mundial, a respeito do tratamento de água com presença de cianobactérias e microcistinas, a partir do string de busca definido (Fonte: Scopus, 2017)

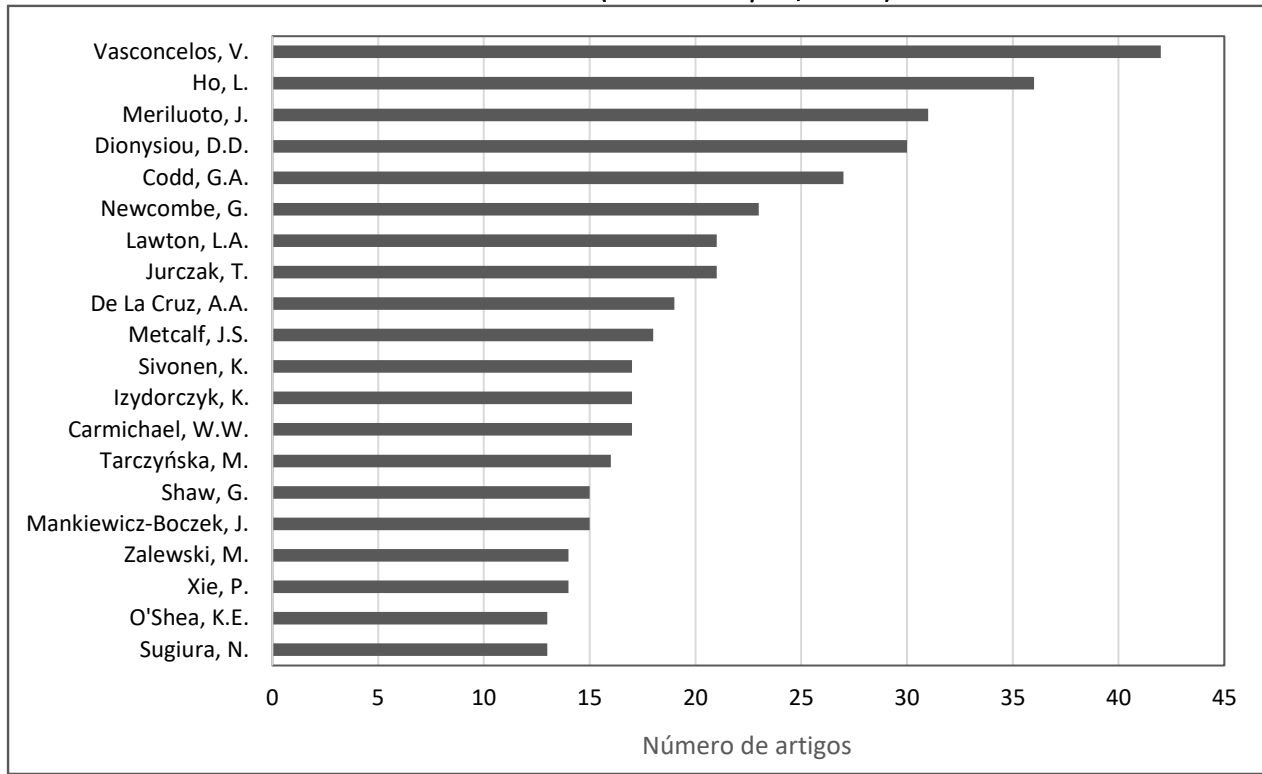

Os autores que publicaram sobre o tema pertencem a 160 instituições de ensino de diferentes origens. As 15 mais importantes, que juntas correspondem a $36 \%$ do total das publicações mundiais, encontram-se representadas na Figura 03, 
com destaque para aChineseAcademyofSciences(primeira e quarta posição da lista de classificação do Scopus), com 103 publicações, o AustralianWaterQuality Centre com 57 publicações e para a Universidade do Porto de Portugal, com 47 publicações.

Figura 03. Distribuição das publicações por Instituiçãode origem, a partir do string de busca definido acerca do tratamento de água com presença de cianobactérias e microcistinas

(Fonte: Scopus, 2017)

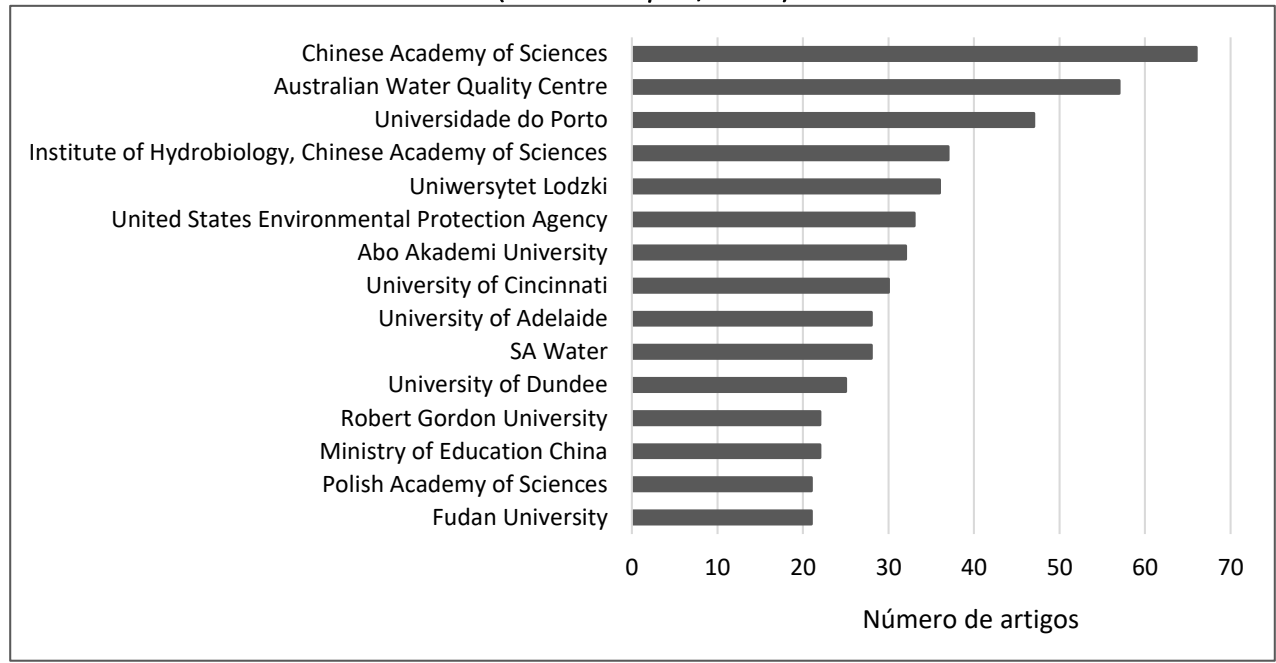

Em relação ao país de origem dos autores, a China apresenta amaior frequência de ocorrência, com 219 publicações, seguida dos Estados Unidos, Austrália, Alemanha, Reino Unido, Polônia e Brasil (em sétimo lugar). A Figura 04 ilustra a relação dos 15 principais países de origem dos autores em número de publicações.

Figura 04. Distribuição das publicações que englobam a questão do saneamento voltadas ao tratamento de água com presença de cianobactérias e cianotoxinas, por país de origem

(Fonte:Scopus, 2017)

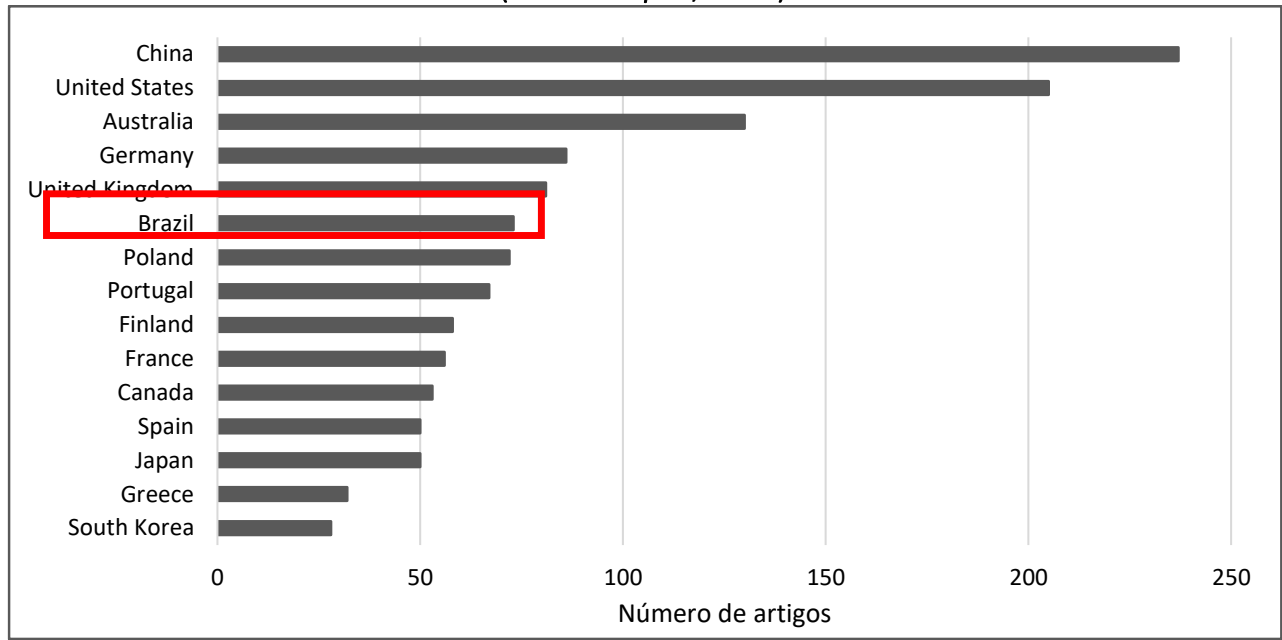

Dos 76 países que possuem publicações referentes ao tema em estudo, o Brasil ocupa lugar de destaque - 70 lugar, com 73 publicações neste período, Os principais autores brasileiros são: Sandra M. F. O. Azevedo, do Laboratório de Ecofisiologia e Toxicologia de Cianobactérias da Universidade Federal do Rio de Janeiro - UFRJ, com pesquisas relacionadas à bioacumulação de cianotoxinas e os 
efeitos na saúde; Odete M. Rocha, do Departamento de Ecologia e Biologia Evolucionária da Universidade Federal de São Carlos, com pesquisas relacionadas à biodiversidade, ecotoxicologia e ecologia de reservatórios; e Ernani Pinto, da Escola de Ciências Farmacêuticas da Universidade de São Paulo - USP, com pesquisas relacionadas a análises de toxinas, peptídeos e produtos naturais de algas e cianobactérias. A Figura 05 ilustra a relação dos 15 principais autores brasileiros em termos de número de publicações considerados por esta pesquisa.

Figura 05. Principais autores brasileiros abrangidos por esta pesquisa, a partir do string de busca definido a cerca do tratamento de água com presença de cianobactérias e microcistinas (Fonte: Scopus, 2017)

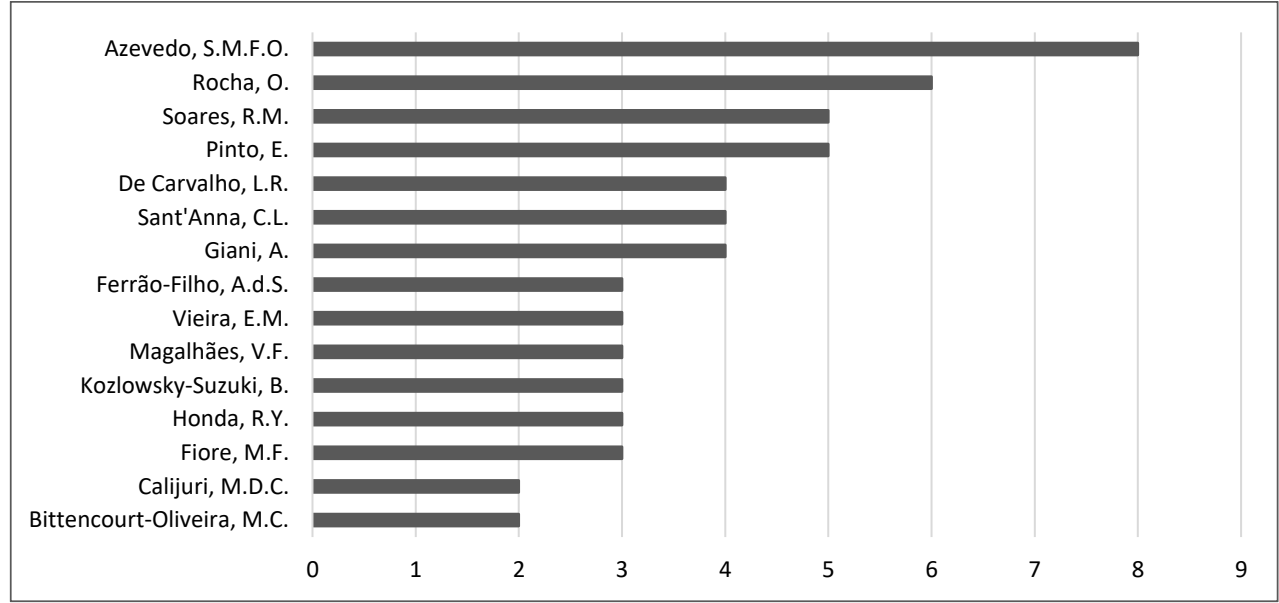

As 10 principais instituições brasileiras que produziram ciência focada em cianobactérias e cianotoxinas estão apresentadas na figura 06. A Universidade de São Paulo (USP) lidera o ranking, com $11 \%$ do total de publicações para o tema, seguida pela Universidade Federal do Rio de Janeiro - UFRJ, com 8\%.

Figura 06. Instituições brasileiras com maior número de publicações a respeito do tratamento de água com presença de cianobactérias e microcistinas, a partir do string de busca definido (Fonte: Scopus, 2017)

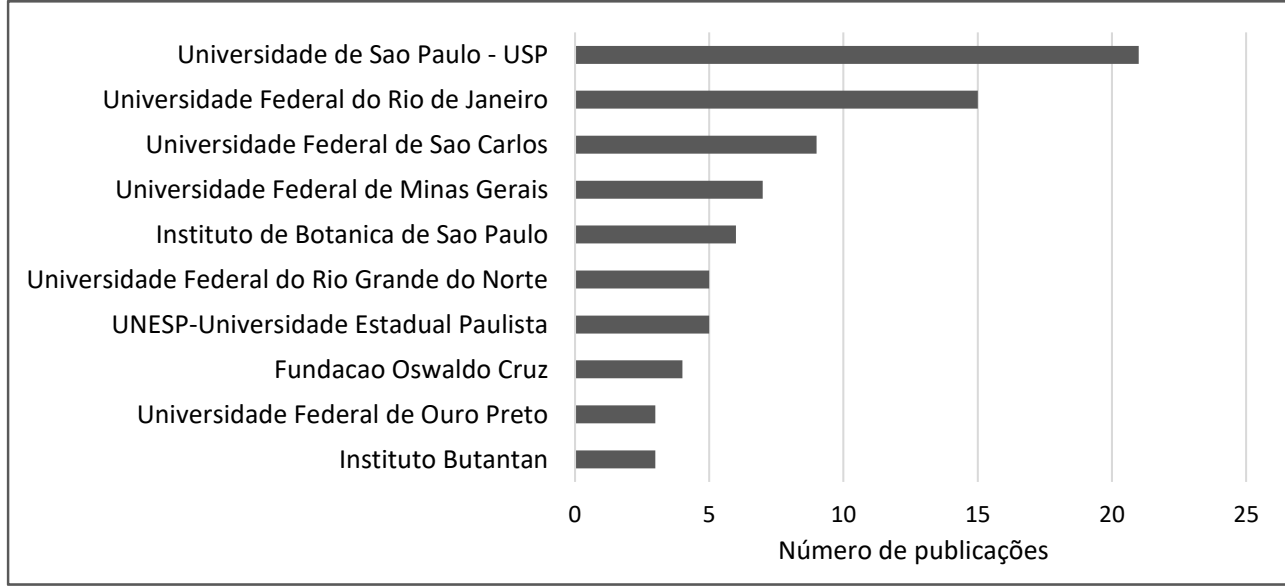

A distribuição das publicações por tipo de documento é apresentada na Figura 07, sendo que os artigos em periódicos lideram largamente o ranking com $79 \%$ (o que representa 978 artigos), seguidos de revisões, com 13\%, de artigos em congressos (3\%), capítulo de livros (3\%), livros (1\%), e as demais categorias (short survey, editorial, carta) com $1 \%$. 
Figura 07. Distribuição geral, a nível mundial, das publicações por tipo de documento(Fonte: Scopus, 2017)

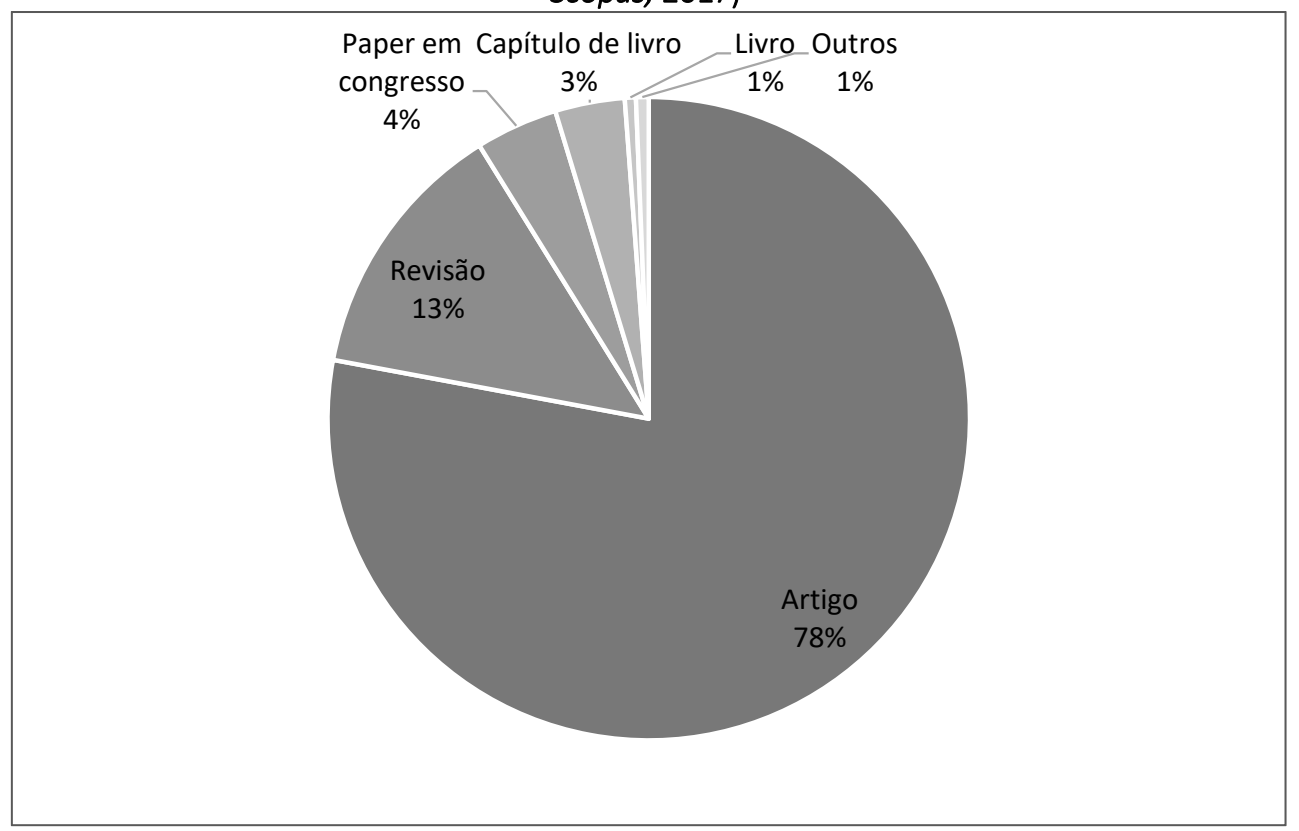

Os 978 trabalhos - modalidade artigos - acima indicados estão distribuídos entre 160 periódicos distintos, interligados ao tema da presente pesquisa. Figura 08 apresenta a distribuição das publicações entre os 10 principais periódicos, sendo os de maior destaque o Toxicon, com 79 artigos, seguido pelo WaterResearch, com 69 artigos, Environmental Science and Technology, com 44, Environmental Toxicology, com 33 artigos,Chemosphere, com 32 artigos, e o Harmfulalgaecom 31 artigos, JournalOfHazardousMaterials, com 27 artigos,Water Science And Technology, com 16 artigos,ChemicalEngineeringJournal, 15 artigos,eo Toxins, também com 15 artigos.

Figura 08. Periódicos com maior número de publicações sobre o tratamento de água com presença de cianobactérias e microcistinas (Fonte: Scopus, 2017)

$\begin{aligned} & - \text { Toxicon } \\ & - \text { Water Research } \\ & - \text { Environmental Science And Technology } \\ & - \text { Environmental Toxicology } \\ & - \text { Chemosphere } \\ & - \text { Harmful Algae } \\ & - \text { Journal Of Hazardous Materials } \\ & - \text { Water Science And Technology } \\ & - \text { Chemical Engineering Journal } \\ & - \text { Toxins } \\ & - \text { Outros }\end{aligned}$




\section{Análise das referências que fundamentam as publicações}

A base de dados exportada para o software BibExcel, identificou uma rede de citações cujo objetivo é distinguir os principais autores que fundamentam as pesquisas, dos demais autores citados nesta análise bibliométrica.

Há um fluxo de interação e integração de conhecimentos da comunidade produtora, na medida em que o conhecimento se constrói por etapas a partir de trabalhos anteriores, e na medida em este se constitui em fundamento para trabalhos posteriores, desta maneira, as citações podem ser interpretadas como manifestações sobre o conhecimento que foi recebido e digerido (ZIMAN, 1969; MORAVCSIK, 1981).

As citações contribuem para o desenvolvimento da ciência, proveem o necessário reconhecimento de um cientista por seus colegas, estabelecem os direitos de propriedade e prioridade da contribuição científica de um autor, constituem importantes fontes de informação, ajudam a julgar os hábitos de uso da informação e mostram a literatura que é indispensável para o trabalho dos cientistas (PRICE, 1974).

Dentro da bibliometria, particularmente a análise de citações permite a identificação e descrição de uma série de padrões na produção do conhecimento científico. Com os dados retirados das citações podese descobrir: autores mais citados, autores mais produtivos, elite de pesquisa, frente de pesquisa, fator de impacto dos autores, procedência geográfica e/ou institucional dos autores mais influentes em um determinado campo de pesquisa; tipo de documento mais utilizado, idade média da literatura utilizada, obsolescência da literatura, procedência geográfica e/ou institucional da bibliografia utilizada; periódicos mais citados, "core" de periódicos que compõem um campo (ARAÚJO, 2006).

Os autores que possuem ao menos uma obra citada mais de quinze vezes compõem a rede de citações representada na figura 09. O tamanho do círculo que compõe os vértices da rede é proporcional ao número de citações. Os autores das obras mais citadas encontram-se destacadas no centro da rede, onde ocorre o maior número de interligações. 
Figura 09. Desenho tridimensional da rede de citações indicando as direções das conexões, o fluxo de informações entre os autores de trabalhos voltados ao tratamento de água com cianobactérias e microcistinas (Fonte: Autoria própria, 2017)

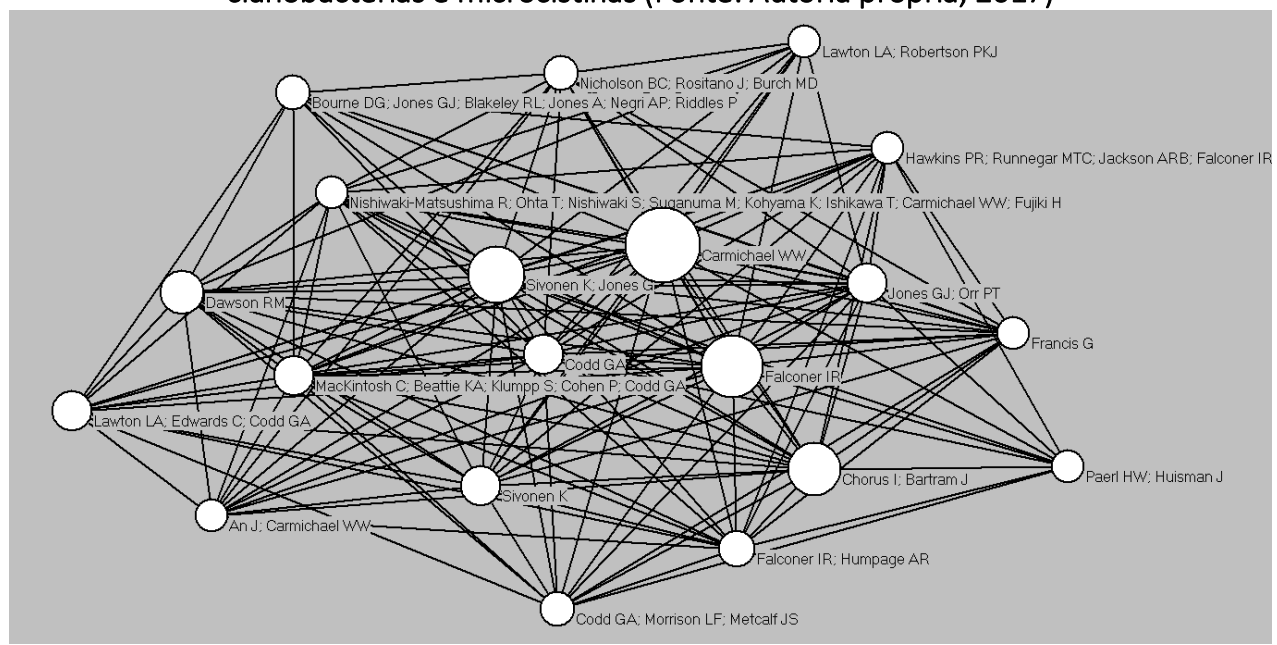

Na figura 10 estão presentes os vinte autores das obras mais citadas, a partir da análise das cocitações. A partir desta análise é possível identificar as obras mais citadas, inferindo-se desta forma seu grau de importância e pioneirismo para a comunidade acadêmica.

Figura 10. Distribuição do número das citações por autor, indicando os autores das principais obras voltadas ao tratamento de água com cianobactérias e microcistinas (Fonte: Autoria própria, 2017)

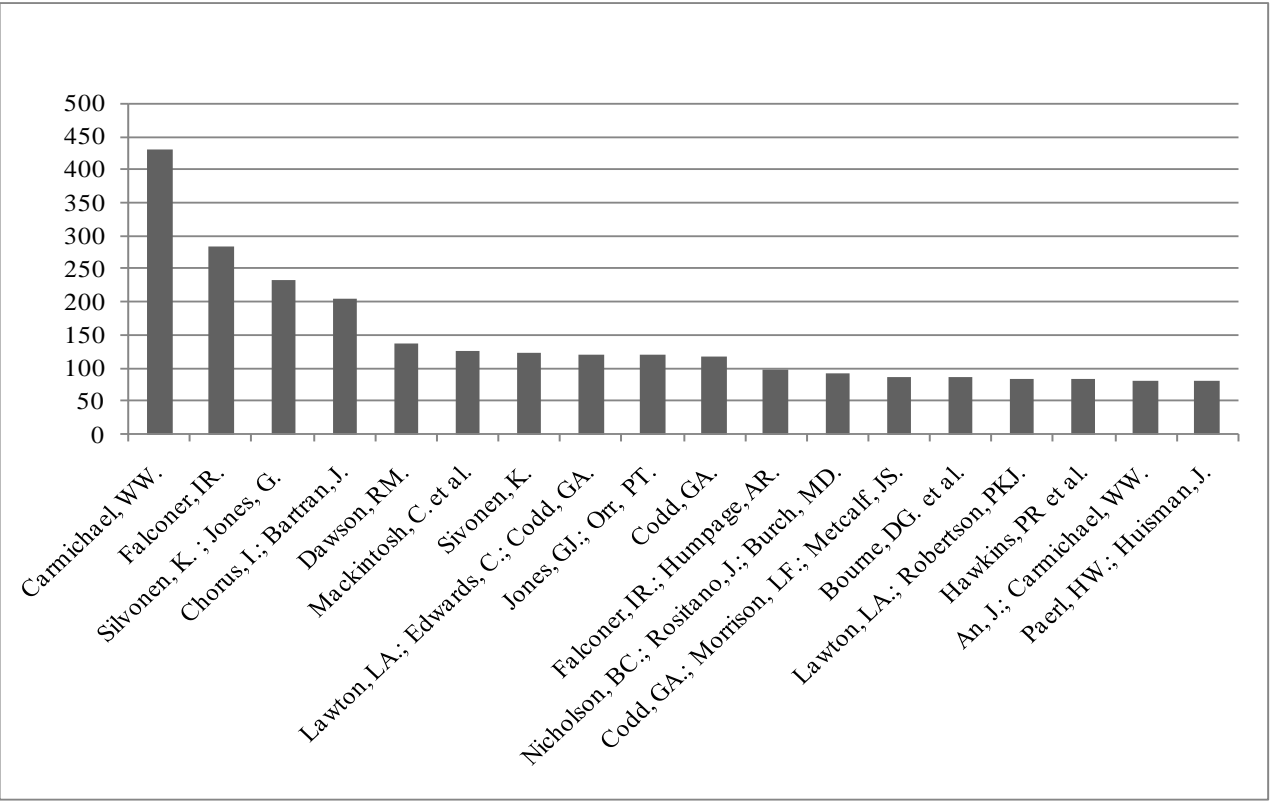

O destaque incide sobre Wayne W. Carmichael, citado 430 vezes nos trabalhos abrangidos por esta pesquisa. $O$ autor americano, da WrithStateUniversity(Dayton, Ohio - Estados Unidos), é pioneiro no assunto, e em um de seus trabalhos mais citados, o reviewintitulado"Cyanobacteriasecondarymetabolites - The cyanotoxins", de 1992, o autor faz uma avaliação das informações disponíveis sobre metabólitos secundários, especialmente das "biotoxinas" de cianobactéria. O autor agrupa as 
toxinas de cianobactérias em duas categorias principais, Neurotoxinas e Hepatotoxinas (por sua vez classificadas como Microcistinas e Nodularinas), baseadas em bioensaios realizados em ratos e invertebrados aquáticos para classificar seu mecanismo de ação. $O$ autor analisa as variantes de microcistinas, caracterizando as diferenças estruturais da molécula que Ihe conferem maior ou menor toxicidade. Além disso, em "The cyanotoxins" (1997) tem relevantes contribuições sobre a detecção, produção e regulação genética de cianotoxinas, avaliação de riscos associados àsmicrocistinase nodularinascomo promotoras de tumores no fígado, informações relativas ao monitoramento, controle e gerenciamento de florações de cianobactéria.

Nesta mesma linha, lan R. Falconer, citado 283 vezes nesta busca, da Universityof Adelaide (Adelaide - Austrália), em um de seus principais artigos "Tumor promotionandliverinjurycausedby oral consumptionofcyanobacteria", de 1991, o autor chama atenção para casos de mortes de animais devido o contato e ingestão de água de reservatórios de abastecimento. $O$ estudo demonstrou que o consumo oral de baixas concentrações de Microcystis por ratos, causa progressivas lesões hepáticas com invasão de leucócitos e morte dos hepatócitos, além de estimular o crescimento de tumores.

O livro intitulado "Toxiccyanobacteria in water: A guidetotheirpublichealthconsequences, monitoringand management", publicado em 1999 pela Organização Mundial da Saúde, reúne autores renomados do mundo todo e é uma das obras mais completas relativas ao tema, distribuída em 13 capítulos.

O livro surgiu para suprir a necessidade da falta de uma literatura abrangente no campo de cianotoxinas, no momento, trazendo de informações básicas a orientações práticas aos interessados, o que acabou por nortear os estudos posteriores, o que justifica sua grande repercussão científica. Ele fornece embasamento para a compreensão do comportamento de cianobactérias e a sua produção de toxinas em condições ambientais, analisa as evidências em relação aos impactos à saúde, principalmente para que os especialistas em saúde pública elaborem orientações ou para a academia identificar e abordar as necessidades de pesquisa. Fornece orientações sobre práticas de segurança no planejamento e gestão da água de abastecimento e de resorts de recreação e lazer, informações sobre prevenção do crescimento de cianobactérias e sua remoção no tratamento de água. Dispõe de orientações sobre a concepção e implementação de programas de acompanhamento e informações sobre métodos laboratoriais para monitoramento de cianobactérias, suas toxinas e as condições para obter seu crescimento em massa. A obra como um todo, além de alguns capítulos em separado, estão entreos trabalhos mais citados desta pesquisa, como é possível observar na Tabela 01. Cabe ressaltar, que os demais autores presentes no gráfico 8 , possuem trabalhos citados na obra.

Tabela 01. Principais obras citadas pelos autores de trabalhos sobre tratamento de água com presença de cianobactérias e cianotoxinas

(continua)

\begin{tabular}{ll}
\hline Autor & Principais obras \\
\hline Carmichael, & - Cyanobacteria secondary metabolites - the cyanotoxins. Journal of \\
W.W. & applied bacteriology, 1992. \\
\hline
\end{tabular}


\begin{tabular}{ll}
\hline & - The cyanotoxins. Advances in botanical research, 1997. \\
Falconer, I.R. & - Tumor promotion and liver injury caused by oral consumption of \\
& cyanobacteria. Environmental toxicology and water quality, 1991.
\end{tabular}

- An overview of problems caused by toxic blue-green algae (cyanobacteria) in drinking and recreational water. Environmental Toxicology, 1999.

Silvonen, K.; - Cyanobacterial toxins. In Chorus, Bartran editors. Toxic cyanobacteria Jones, G. in water: WHO, 1999.

Chorus, I; - Toxic cyanobacteria in water: A guide to their public health

Bartran, J. consequences, monitoring and management. Spon Press, 1999.

(editors)

Hawkins, P. R. et - Isolation and toxicity of Cylindrospermopsisraciborskii from an al. ornamental lake. Toxicon, 1997.

- Severe hepatotoxicity caused by the tropical cyanobacterium (bluegreen alga) Cylindrospermopsisraciborskii (Woloszynska) Seenaya and SubbaRaju isolated from a domestic water supply reservoir. Appl. Environ. Microbiol., 1985.

Falconer, I. R. e - Tumour promotion by cyanobacterial toxins. Phycologia, 1996.

Humpage, A.R.

Ohtani, I., et al. - Cylindrospermopsin, a potent hepatotoxin from the blue-green alga Cylindrospermopsisraciborskii. J. Amer. Chem. Soc., 1992.

Dawson, R. M. - The toxicology of microcystins. Toxicon, 1998.

Codd, G.A.

- Cyanobacterial poisoning hazard in British freshwaters. Vet. Rec., 1983.

Sivonen, K. - Effects of light, temperature, nitrate, orthophosphate, and bacteria ongrowth of and hepatotoxin production by Oscillatoriaagardhii strains. App. Environ. Microbiol., 1990.

- Cyanobacterial toxins and toxin production. Phycologia, 1996.

- Toxic Cyanobacteria in Finnish Fresh Waters and the Baltic Sea. Reports from Department of Microbiology, 1990.

MacKintosh, $C$. et Cyanobacterialmicrocystin- $L R$ is a potent and specific inhibitor of protein al. phosphatases 1 and $2 A$ from both mammals and higher plants. Fed. Eur. Biochem. Soc. Lett.,1990.

Lawton, L. et al. - Determination of cyanobacteria in the laboratory. In Chorus, Bartran editors. Toxic cyanobacteria in water: A guide to their public health consequences, monitoring and management. London: Spon Press, 1999.

Paerl, H. W., - Blooms like it hot. Science-New York Then Washington, 2008.

Huisman, J. - Climate change: a catalyst for global expansion of harmful cyanobacterial blooms. Environmental Microbiology Reports, 2009.

Jones, G.J - Limnological study of cyanobacterial dominance in three South-East Queensland reservoirs. In: R.R.D. Davis [Ed.] Managing Algal Blooms: Outcomes from the CSIRO Blue-Green Algal Research Program. CSIRO Land and Water, 1997.

Humpage, A. - Microcystin-LR and liver tumour promotion: effectson cytokinesis, ploidy, and apoptosis in cultured hepatocytes. Env. Toxicol. Water Qual., 1999. 
Banker, R. et al. - Identification of cylindrospermopsin in Aphanizomenonovalisporum (Cyanophyceae) isolated from Lake Kinneret, Israel1. Journal of Phycology, 1997.

Chorus, I. - - Die Blaualgen ("Cyanobakterien") - eine Berliner Besonderheitwelcher ZusammenhangbestehtzwischendemMassenhaftenAuftreten von Blaualgen und der Nutzung von Badegewässern? In: NachhaltigkeitimWasserwesen in der MitteEuropas, 1998.

Byth, S. - Palm Island mystery disease. Med. J. Aust., 1980.

\section{Análise geral das publicações}

A partir da análise geral das publicações, foi possível verificar a diversidade da evolução dos métodos de tratamento de água, estes através de mecanismos físicos, químicos, biológicos ou combinados, para degradação e remoção tanto de células de cianobactérias, quanto de cianotoxinas dispersos de forma livre da água. Albuquerque Junior (2006) salienta que o maior desafio tem sido desenvolver um método que alie eficiência a baixos custos operacionais e fácil manipulação para os sistemas de tratamento de água.

O tratamento biológico de água contaminada com cianotoxinas vem sendo explorado a partir do emprego de diversas metodologias, como em filtros lentos de areia biologicamente ativados, biorreatores de leito fluidizado, além de estudos de cepas bacterianas, plantas aquáticas e substancias bioativas de plantas capazes de degradar diversas variantes de microcistinas (MCs).

Estudos referentes à remoção de biomassa de cianobactérias e microalgas começaram a ser publicados ainda na década de 1970. A eficiência do tratamento físico-químico, dentro do qual se encaixa o chamado "tratamento convencional", que compreende as etapas de coagulação, floculação, sedimentação e filtração, teve sua eficácia questionada para o tratamento de água com cianobactérias e suas toxinas, principalmente no que tange àretirada das frações dissolvidas de toxinas do meio. Ainda em 1976, Hoffman propôs a utilização da adsorção em carvão ativado em pó (CAP), revelando resultados promissores para a época. Keijolaet al. (1988), por sua vez, apresentaram a adsorção em carvão ativado granular (CAG) como um método efetivo na remoção de hepatotoxinas e neurotoxinas. Falconeret al. (1989) e Himberget al.(1989), também avaliaram a remoção de toxinas por CAP e CAG. Os resultados de ambos os trabalhos sugerem que o carvão ativado seria capaz de remover cianotoxinas sozinho ou de forma combinada com o tratamento convencional.

A partir da segunda metade da década de 1990, ocorreram avanços na pesquisa da remoção de MCs por CAP e CAG, pois se inseriu a estes estudos a relação da porosidade do material precursor, o modo de ativação dos carvões, a presença de matéria orgânica dissolvida, o pH e sua influência na capacidade de adsorção dos mesmos para as cianotoxinas, sendo que, desta forma, melhores resultados foram alcançados.

Métodos físicos de tratamento de água para retirada de cianobactérias e cianotoxinas, como a osmose reversa e membranas de microfiltração (MF), nanofiltração (NF) e ultrafiltração (UF), têm sido investigados, demonstrando que é uma alternativa eficiente para a remoção tanto de células quanto de vários 
análogos de microcistinas, porém, o fator limitante destas tecnologias ainda está relacionado ao seu alto custo.

Os tratamentos combinados vêm ganhando espaço no cenário mundial. Jurczaket al. (2005) relataram a eliminação de MCs em um caso prático, da água de abastecimento da cidade de Lodz (Polônia), a partir "SulejowReservoir", utilizando-se de pré-oxidação, coagulação, filtração por areia, ozonização e cloração. O tratamento usado mostrou-se efetivo em 2002 e 2003. Dixonet al. (2011) utilizaram uma abordagem de múltiplas barreiras incorporando coagulação, CAP e UF. A coagulação foi usada para remover as células e a toxina intracelular, enquanto o CAP foi utilizado para a adsorção da toxina extracelular e, finalmente, a UF foi usada para retirada dos flocos.

Camacho et al. (2015) avaliaram o processo coagulação/floculação/flotação por ar dissolvido/nanofiltração, utilizando sementes de Moringa oleifera como coagulante natural, para remoção de Microcystis protocystis e MC-LR. Resultados satisfatórios foram alcançados para remoção das células, cor e turbidez, mas somente o processo associado a nanofiltração removeu completamente a toxina dissolvida (10 $\mu \mathrm{g} . \mathrm{L}-1$ de microcistina-LR).

Devido à infinidade de técnicas e àgrande diversidade de cianotoxinas identificadas atualmente, optou-se por restringir a análise das publicações, voltando-se para os métodos químicos de tratamento de água aplicados de maneira singular ou combinados, para degradação e remoção de cianotoxinas da água, focando principalmente nos casos práticos para remoção de MC-LR, que serão abordados a seguir.

\section{Processos químicos de tratamento de água com Microcistina-LR}

Métodos alternativos às técnicas convencionais (coagulação, floculação, sedimentação, filtração, adsorção em carvão ativado, flotação por ar dissolvido), que envolvem a oxidação de poluentes com reagentes como o ar ou o oxigênio em fase aquosa, tais como a oxidação supercrítica, a oxidação eletroquímica e o uso de permanganato de potássio, cloro, peróxido de hidrogênio ou ozônio, tem sido estudadas recentemente. Dentre estas técnicas, os processos avançados de oxidação (AOPs) aparecem como os mais promissores para aplicação em água e solos contaminados, por promoverem a degradação total de uma grande variedade de poluentes, e poderem levar à formação de contaminantes menos poluentes (compostos orgânicos oxigenados e ácidos de baixo peso molecular) (PERA-TITUS, et al. 2004).Há uma variedade de agentes oxidantes que são frequentemente empregados para o tratamento de água. Os principais são: radical hidroxila, ozônio, peróxido de hidrogênio, radical perhidroxila, permanganato, ácido hipocloroso, cloro, dióxido de cloro.

\section{a) Processos Químicos Convencionais}

\section{Cloro, Dióxido de Cloro e Permanganato}

O cloro tem sido usado como reagente de purificação de água desde o início do século 20 nos Estados Unidos, substituindo a filtração de areia como o método 
de desinfecção (LAWTON e ROBERTSON, 1999). MCs e nodularinas podem ser rapidamente destruídas por cloro, hipoclorito de cálcio e hipoclorito de sódio, no último caso exigindo dosagens superiores. $\mathrm{O} \mathrm{pH}$ mostrou-se um fator relevante, pois a remoção de toxinas foi drasticamente reduzida em $\mathrm{pHs}$ maiores que 8 (NICHOLSON, ROSITANO e BURCH, 1994). Tsuji et al. (1997) demonstraram por seus estudos alta eficiência da cloração com hipoclorito de sódio na decomposição de MC-LR e MC-RR. Porém, os autores advertem que a préoxidação das células com cloro deve ser evitada pois causa lise celular e produz trihalometanos durante o processo de tratamento de água.

Ho et al. (2006) estudaram a remoção de análogos de MCs diante da sua exposição ao cloro, observando-se a remoção com demanda de cloro acima de 25 mg.L-1 na seguinte ordem: MC-YR>MC-RR > MC-LR > MC-LA. Porém, diversos autores mostraram que a utilização de dióxido de cloro e cloroaminas na remoção de cianotoxinas da água, não são eficazes (NICHOLSON; ROSITANO; BURCH, 1994; HART, FAWELL e CROLL, 1998).

Valores de $\mathrm{pH}$ usualmente praticáveis necessitam de um maior tempo de contato com a molécula de $\mathrm{MC}$, além disso, concentrações apropriadas de cloro residual livre devem ser garantidas. A remoção de MCs por cloração foi mais eficiente em pH 6 com uma concentração residual de cloro entre 0,5 e 1,0 mg.L-1 (HRUDEY et al., 1999). Corrobora com estes dados, os resultados de Xagorarakiet al. (2006) e Acero et al. (2008), onde foram avaliados os efeitos da variação do $\mathrm{pH}$, demonstrando que a oxidação de MC-LR com cloro depende do pH. No estudo de Xagorarakiet al. (2006) melhores remoções ocorreram com pH 6, e remoções mais lentas em pH 9. Acero et al. (2008) também verificou que altas concentrações de amônia consomem cloro, impedindo a eliminação de MC-LR. Já durante a oxidação com permanganato, a oxidação de MC-LR não é afetada pelo $\mathrm{pH}$ e pelo teor de amônia.

O permanganato é um forte agente oxidante capaz de destruir compostos orgânicos e microrganismos, a sua aplicação em larga escala começou na década de 1960 nos Estados Unidos e na Europa (LAWTON; ROBERTSON, 1999). Rositano et al. (1998) demonstraram que uma solução de $1 \mathrm{mg} \mathrm{dm}-3$ de permanganato de potássio removeu $95 \%$ de uma solução de $200 \mu \mathrm{g} \mathrm{dm}-3$ de MC-LR em 30 minutos. Em comparação a oxidação com uso de cloro e permanganato de potássio demonstrou uma remoção mais rápida de MC.

Ho et al. (2009) avaliaram a pré-oxidação com permanganato de potássio para remoção de geosmina e saxitoxinas produzida por uma cepa de cianobactéria da espécie Anabaenacircinalis, indicando ser esta tecnologia uma boa alternativa, pois não libera geosmina e saxitoxina intracelular para o meio.

\section{b) Degradação Eletroquímica}

Mais recentemente a degradação eletroquímica de cianotoxinas tem sido avaliada a partir de diferentes sistemas. Lianget al.(2008) estudaram a degradação de MC-LR usando Ti/RuO2, os resultados mostraram que a eficácia da remoção de MC-LR total aumenta em menores densidades celulares e em maiores intensidades de corrente. Remoções de MC-LR superiores a 98\% foram atingidas tanto em águas naturais quanto em água potável. Zhang et al. (2009) 
avaliaram a degradação eletroquímica de MC-RR usando eletrodo de boro dopado com diamante, os resultados demonstraram que a remoção eficiente de MC-RR ocorreu apenas na presença de cloreto de sódio, que atuou como mediador redox, outro fator determinante também foi a densidade de corrente aplicada.

Jeon et al. (2015) avaliaram a degradação eletroquímica de Microcystisichthyoblabe e MC-LR, porém, neste caso a eficiência de remoção foi insensível a variações da densidade celular, concentração inicial de MC-LR e condutividade, dependendo fortemente da suspensão algal. Garcia et al. (2015) avaliaram o processo de fotoeletrooxidação na degradação MCs. Os resultados mostram que a potência da radiação UV e da corrente elétrica estão diretamente associados com a degradação de toxinas. O sistema proposto é eficiente na remoção de MCs, onde a redução chegou a $99 \%$.

\section{c) Processos Avançados de Oxidação (AOP's)}

Vários processos de produção de radical hidroxila têm sido estudados e dentre os principais estão a fotólise, a fotocatálise e a oxidação com o ar, com peróxido de hidrogênio e ozônio, além dos sistemas combinados constituídos de oxidantes, adsorventes e catalisadores.

A oxidação fotolítica tem sido reportada por muitos pesquisadores, através de uma série de métodos. Para levar à fotodegradação, é necessário que o composto absorva a luz no mesmo comprimento de onda emitido pela fonte de luz. Se este não for o caso a clivagem fotolítica pode ser atingida com um agente sensibilizador que absorve a luz e inicia a reação de decomposição (LAWTON; ROBERTSON, 1999).

A fotocatálise consiste de utilização de uma fonte de radiação associada a um catalisador. Vilela et al. (2012) investigaram o uso da fotocatálise heterogênea solar (TiO2) na degradação de MC-LR.Foram necessários 150 minutos de ensaios $(\mathrm{pH} 3)$ para reduzir de 10 para $1 \mu \mathrm{g} . \mathrm{L}-1$ de MC-LR, a toxicidade aguda presente na amostra inicial foi removida, porém, houve a formação de subprodutos com efeitos crônicos em mamíferos.

Lawton et al. (2003) avaliaram a degradação de variantes de MCs por fotocatálise com TiO2 e radiação UV, e concluíram que alterações na molécula de $M C$, provocam alterações na hidrofobicidade da molécula global,o que reflete na adsorção da molécula por TiO2 e influencia diretamente na eficiência do processo com adição de radiação UV.

Por fim, dentre os métodos avançados de oxidação estão a oxidação com o ar, com peróxido de hidrogênio e ozônio. Alguns estudos mostraram que a demanda de ozônio está intimamente ligada a presença de compostos orgânicos. O estudo de Hart e Stott (1993) e Carlile (1994) demonstraram que menores doses de ozônio foram necessárias para a degradação de MCs na água tratada comparada com água bruta. Carlson (1993), Bose; Boiijayanta; Reckhow (1994) e Andrews; Huck (1994) ainda mostraram que a concentração e a natureza da matéria orgânica natural, o pH e a concentração de carbonato na água também estão associados a demanda de ozônio. 
O aumento da degradação de MCstambém está associado a altas doses de ozônio bem como do tempo de contato entre a toxina e este oxidante, porém devem ser observados que altas doses podem acarretar doses significativas de ozônio residual em solução (ROSITANO, 1996).

Rositanoet al. (1998) mostraram uma eficiência de remoção de MCs acima de $99 \%$ utilizando uma dose de ozônio, 0,05 mg.L-1 por 5 segundos de contato. Anos mais tarde Rositanoet al. (2001) estudaram a ozonização de quatro águas tratadas com qualidades muitodiferentes contaminadas artificialmente com MC-LR, MC-LA e anatoxina-a, atingindo $100 \%$ de degradação das MCs, porém a anatoxina-a foimuito resistente ao ozônio. Desta forma a água contaminada com esta toxina necessitaria de um tratamento a mais, tal como carvão ativado granulado.

Lawton; Robertson (1999) advertem que o ozônio é um gás instável, com alto potencial de oxidação e é utilizado para o tratamento de água por dispersão do gás no meio aquoso. Embora amplamente utilizado para o tratamento de água potável, é um reagente dispendioso e por vezes imprevisível.

Sistemas combinados de tratamento de água com microcistinas

\section{a) Carvão ativado associado a oxidantes}

Hoeger, Dietrich e Hitzfeld (2002) investigaram o efeito da ozonização na remoção de toxinas de cianobactérias durante uma sequência de tratamento envolvendo um reator de batelada em escala de laboratório, com subsequente etapa de filtração em areia e carvão ativado. A alta concentração de carbono orgânico total na água bruta utilizada levou à redução da eficiência da oxidação e destruição de toxina livre. Além disso, a ozonização de águas brutas contendo alta densidade de células de cianobactérias resultou na lise das células e liberação de toxina intracelular.

Em 2002, Newcombeet al. avaliaram a ozonização e adsorção em carvão ativado quimicamente a base de madeira e biodegradação na remoção de MCs presentes em diferentes águas brutas. Ambas as MCs (MC-LR e MC-LA) apresentaram o mesmo comportamento de degradação por ozonização,sendo destruídas por doses de ozônio de 0,5 e $1 \mathrm{mg}$.L-1 após 5 minutos. A análise da toxicidade dos subprodutos da ozonização por bioensaios, revelou que os subprodutos de ambas toxinas não foram tóxicos.

\section{b) Sistemas homogêneos associados a oxidantes}

Liu et al. (2010) analisaram o efeito da radiação UV (254 nm) seguida de ozonização para remoção de MC-LR. Os produtos de decomposição da toxina foram analisados por UHPLC (Cromatografia Líquida de Ultra Alta Performance), e a redução de toxicidade através de estudos da inibição da proteína fosfatase. Os resultados indicaram que o processo UV/O3, em comparação com os efeitos isolados (somente UV e O3) diminui efetivamente a concentração e a toxicidade 
da MC-LR a $100 \mu \mathrm{g}$. L-1 após 5 min de irradiação UV e consequente ozonização a 0,2 mg. L-1 por $5 \mathrm{~min}$, enquanto foi necessária dosagem de 0,5 mg. L-1 de ozônio para o níveis inferiores a 0,1 $\mu \mathrm{g}$. L-1.

Qiaoet al. (2005) investigaram a degradação da MC-RR por um sistema catalítico combinado, composto por UV/H2O2. A eficiência de degradação de MCRR não aumentou linearmente com o aumento da intensidade da luz UV e dosagem do peróxido de hidrogênio. Comparado com o tratamento usando individualmente a radiação de UV e peróxido de hidrogênio, o sistema combinado UV/H2O2 melhorou significantemente a eficiência de remoção daquela toxina de água devido ao efeito sinergético entre o modo de oxidação por radiação UV e peróxido de hidrogênio.

He et al.(2011) avaliaram a degradação de MC-LR por processo UV-C/H2O2, investigou-se a influência da radiação UV, da dose de oxidante, concentração de MC-LR, além da presença de matéria orgânica natural, $\mathrm{pH}$ e alcalinidade, sobre a degradação. O H2O2 reage como um iniciador ou inibitor, dependendo da concentração. Nas condições de estudo (UV de 0,27 mW/cm2 e $1 \mu \mathrm{M}$ de MC-LR), a concentração ótima de $\mathrm{H} 2 \mathrm{O} 2$ foi de 882 mM.

Água filtrada de um sistema hidráulico foi enriquecida com MC-LR e tratada com radiação UV ( $254 \mathrm{~nm}$ ) e ozonização (UV/O3). Os resultados da comparação dos três processos (O3, UV e UV+O3), indicaram que o processo UV/O3 pode efetivamente diminuir tanto a concentração quanto a toxicidade da MC-LR ao nível de $100 \mu \mathrm{g} . \mathrm{L}-1$, após 5 min de irradiação UV e consequente ozonização por 5 min a 0,2 mg.L-1 (abaixo de 1 $\mu \mathrm{g} . \mathrm{L}-1$ ), enquanto que uma dose de 0,5 mg.L-1 de ozônio foi necessária para reduzir o nível abaixo de 0,1 $\mu \mathrm{g}$.L-1.

Huoet al., (2015) investigaram o efeito do H2O2 sobre a integridade celular de Microcystis aeruginosa, e sobre a liberação e degradação de MCs expostas ao espectro de luz solar fornecida por lâmpada de vapor de mercúrio de alta pressão. Mais de $99 \%$ das células $M$. aeruginosa foram rompidas ou danificadas em $3 \mathrm{~h}$ para todos os tratamentos, e a liberação de MCs para a amostra foi estreitamente correlacionada com a perda da integridade da célula.

\section{c) Catalisadores heterogêneos associados a oxidantes}

He et al.(2015) investigaram a degradação das variantes comuns de MCs em água, MC-LR, MC-RR, MC-YR e MC-LA, por processos baseados em UV $254 \mathrm{~nm}$, somente UV, UV/H2O2, UV/S2O82- e UV/HSO5-. Observou-se que a fotólise direta de MCs é limitada, enquanto que a adição de um oxidante melhora significativamente a eficiência da degradação. A remoção de MC-LR por processo UV/H2O2 aparentou ser mais rápida devido à presença do radical hidroxila.

Tecnologias avançadas de oxidação à base de sulfato (SR-AOTs) associadas a fotólise, termólise e mecanismos de transferência de elétrons foram avaliadas para a degradação do MC-LR por Antoniou, Armah e Dionysiou (2010). A geração de radicais sulfato se deu pela ativação de oxidantes persulfato (PS) e peroximonossulfato (PMS) por meio de cátions de metais de transição eletrofílicos (Ag+ e Co2+, respectivamente), radiação (UV $300<\lambda<400 \mathrm{~nm}$ ) e / ou de calor $\left(\mathrm{T}=30^{\circ} \mathrm{C}\right)$. Quando comparados ao reagente de Fenton e $\mathrm{H} 2 \mathrm{O} 2$ 
juntamente com o calor e radiação, com base nas condições de pH ótimas para cada sistema, a ordem de eficácia foi Co2+/PMS> Fe2+/H2O2 »Ag+/PS.

Wang et al. (2014) utilizaram bentonita com nanopartículas de $\mathrm{Fe} / \mathrm{Pd}$ suportadas para remover MC-LR, 96,86\% da MC-LR foi removido usando o sistema, enquanto apenas $81,76 \%$ e $10,06 \%$ de MC-LR foram removidos usando nanopartículas de $\mathrm{Fe} / \mathrm{Pd}$ e bentonita após $3 \mathrm{~h}$, respectivamente.

Fenget al. (2006) estudaram a degradação fotocatalítica de MC-LR utilizando película fina de nanopartículas de TiO2, com irradiação UVA de baixa intensidade, a análise demonstrou que a degradação da toxina foi influenciada pelo $\mathrm{pH}$, concentração inicial e intensidade da radiação UV, 95\% de $20 \mu \mathrm{g}$.L-1 MC-LR foi decomposta em 120 minutos sob iluminação UV a $400 \mathrm{~mW} / \mathrm{cm} 2 \mathrm{em} \mathrm{pH} \mathrm{4,} \mathrm{sendo}$ esta a melhor condição.

Choiet al. (2007) avaliaram a atividade fotocatalítica de mesoporos de nitrogênio dopados com TiO2 ( $\mathrm{N}$-TiO2) para destruição de MC-LR. Mesmo sob luz UV, MC-LR foi decomposta 3-4 vezes mais rápida usando N-TiO2 do que apenas TiO2.

\section{d) Catalisadores heterogêneos suportados}

Lee et al. (2004) exploraram o potencial do carvão ativado revestido com TiO2, as funções combinadas da elevada área superficial do carvão ativado somada as propriedades do TiO2 mostraram efeito sinérgico sobre a degradação de MC-LR, onde ela foi degradada em produtos não tóxicos e $\mathrm{CO} 2$ muito rapidamente.

Pestana et al. (2015) avaliaram o potencial de esferas de vidro ocas revestidas com TiO2, empregadas na degradação fotocatalítica de onze variantes de MCs e nodularinas em água. Verificou-se que as toxinas foram decompostas com êxito em todos os casos em 5 minutos ou menos.

\section{CONCLUSÃO}

A água é um tema de fundamental importância para o desenvolvimento urbano. Todas as atividades desenvolvidas nas cidades precisam de água, por isso ela deve estar no centro do planejamento econômico, pois o crescimento de determinado setor, como o industrial, acarreta diretamente a diminuição da disponibilidade de água para outros usos, como o abastecimento doméstico.

O presente trabalho apresentou resultados quantitativos relacionados ao aumento de pesquisas relacionadas à tratabilidade da água com cianobactérias e cianotoxinas, preocupação impulsionada pelo surgimento de florações tóxicas de cianobactérias, o que está totalmente ligado a degradação ambiental. O planejamento urbano deve contemplar medidas de preservação em toda a bacia hidrográfica: medidas integradas e preventivas. Quando não ocorre o planejamento e investimentos adequados, com a participação pública, são necessárias medidas corretivas. Por isso o desenvolvimento de pesquisas envolvendo o tratamento avançado de água são necessárias.A gravidade dos 
riscos associados à presença de cianobactérias em reservatórios de abastecimento de água é um problema real, reconhecido amplamente pela comunidade acadêmica internacional, fato este que se nota pelo montante de publicações e repercussão dos trabalhos.

A análise geral das publicações permitiu estabelecer um panorama da evolução tecnologias de tratamento desenvolvidos ao longo dos anos, suas mudanças e aprimoramentos, até chegar ao cenário atual. Um fator a ser considerado é a escala dos estudos e a aplicabilidade práticados mesmos, tendo em vista que muitos deles, apesar de eficientes, são bastante onerosos e, por esse motivo, inviáveis economicamente (como a oxidação por 03). Outros métodos se destacam pela eficiência e pelo baixo custo, porém os resultados são mais demorados (filtros de areia biologicamente ativados).A associação de diferentes tecnologias para um eficiente tratamento da água tem sido relatada, e parece ser o melhor caminho para o alcance de resultados positivos e viáveis economicamente. Sendo assim, a incorporação de etapas estratégicas e eficientes ao sistemaconvencional de tratamento, que permite utilizar também a estrutura física já existenteé uma alternativa que merece atenção. 


\title{
Cianobacteria, cyanotoxins and the chemical treatment of water: a bibliometric analysis of world scientific production
}

\begin{abstract}
This work presents the results of a bibliometric analysis carried out with the aim of analyzing the world scientific production on cyanobacteria, cyanotoxins and the chemical treatment of water. Due to the myriad of techniques and the great diversity of cyanotoxins currently identified, it was decided to restrict the analysis of the publications, turning to the unique or combined applied water treatment chemical methods for the degradation and removal of cyanotoxins from water, focusing mainly on the practical cases for removal of MC-LR. At first, the profile of the publications was analyzed, identifying which were the periodicals most used for the dissemination of research, the geographical and institutional origin of the authors and the bibliography used, as well as the analysis of citations and networks of relationships established worldwide, relating to scientific publications on cyanobacteria, cyanotoxins and water treatment. In numerical terms, the bibliometric data of 1255 papers published between 1980 and June 2017 were analyzed. The year of 2013 had the highest number of publications since 1980.
\end{abstract}

KEY WORDS:Scientific production. Cyanobacteria. Water Supply. Water treatment. 


\section{REFERÊNCIAS}

ACERO, J. L. etal.Oxidation of microcystin-LR with chlorine and permanganate during drinking water treatment. Journal of Water Supply: Research and Technology-AQUA, v. 57, n. 6, p. 371-380, 2008.

ALBUQUERQUE JUNIOR, E. C. Produção e Caracterização de Carvão Ativado Para Remoção de Microcistinas. Tese (Doutorado). Faculdade de Engenharia Química da Universidade Estadual de Campinas - UNICAMP, 2006.

ARAÚJO, C. A. Bibliometria: evolução histórica e questões atuais. EmQuestão, Porto Alegre, v. 12, n. 1, p. 11-32, 2006.

BANKER, R.et al.Identification of cylindrospermopsin in Aphanizomenonovalisporum (Cyanophyceae) isolated from Lake Kinneret, Israel. Journal of Phycology, v. 33, n. 4, p. 613-616, 1997.

BYTH, S. Palm Islandmysterydisease. The Medical Journal of Australia, v. 2, n. 1, p. 40,42, 1980.

CAMACHO, F. P. etal.Coagulation/flocculation/flotation/nanofiltration processes using MoringaOleifera as coagulant of Eutrophized river. Chemical Engineering Transactions,V. 43, 2015.

CASTENHOLZ, R.W.; WATERBURY, J.B. In: STALEY, BRYANT, PFENNIG and HOLT, editors. Bergey's Manual of Systematic Bacteriology. Vol. 3, Williams \& Wilkins, Baltimore, 1710-1727, 1989.

CARMICHAEL, W. W. Cyanobacteria secondary metabolites - the cyanotoxins.Journal of applied bacteriology, v. 72, n. 6, p. 445-459, 1992.

CARMICHAEL, W. W. The cyanotoxins.Advances in botanical research, v. 27, p. 211257, 1997.

CHORUS, I. Die blaualgen ('Cyanobakterien')-eine Berliner BesonderheitwelcherZusammenhangzwischendemMassenhaftenAuftreten von Blaualgen und der Nutzung von Badegewässern. In: Nachhaltigkeit in Wasserweswn in der MitteEuropas, Symposium Berlin (D). 1998. p. b29. 
CHORUS, I.; BARTRAN, J. (Editors). Toxic cyanobacteria in water: A guide to their public health consequences, monitoring and management. London: Spon Press, 1999.

CODD, G.A. Cyanobacterial poisoning hazard in British fresh waters.Vet.Rec., 113, 223-224, 1983.

DIXON, M. B. etal.A coagulation-powdered activated carbon-ultrafiltrationMultiple barrier approach for removing toxins from two Australian cyanobacterial blooms. Journalofhazardousmaterials, v. 186, n. 2, p. 1553-1559, 2011.

FALCONER, I. R.; RUNNEGAR, M. T. C.; BUCKLEY, T.; HUYN, V. L.; BRADSHAW,P. Using activated carbon to remove toxicity from drinking water containing cyanobacteriablooms. Journa1 American ofWater Works Association, v.81, p.I02105, 1989.

FALCONER, I. R. An overview of problems caused by toxic blue-green algae (cyanobacteria) in drinking and recreational water. Environmental Toxicology, v. 14, n. 1, p. 5-12, 1999.

FALCONER, I. R. Tumor promotion and liver injury caused by oral consumption of cyanobacteria. Environmental toxicology and water quality, v. 6, n. 2, p. 177-184, 1991.

FALCONER, I.R.; HUMPAGE, A.R. Tumour promotion by cyanobacterial toxins. Phycologia, 35 (6 supplement), 74-79, 1996.

GARCIA, A. C. A. et al.Degradation of cyanotoxins (microcystin) in drinking water using photoelectrooxidation. Brazilian Journal of Biology, v. 75, n. 2, p. 45-49, 2015.

HART, J.; FAWELL, J. K.; CROLL, B.The fate ofboth intra- and extracellular toxins during drinking water treatment.Water Supply, v.16, n. 112, p.61I-616, 1998.

HAWKINS, P.R., CHANDRASENA, N.R., JONES, G.J., HUMPAGE, A.R. AND FALCONER, I.R. Isolation and toxicity of Cylindrospermopsisraciborskii from an ornamental lake.Toxicon, 35, 341-346, 1997.

HAWKINS, P. R. et al. Severe hepatotoxicity caused by the tropical cyanobacterium (blue-green alga) Cylindrospermopsisraciborskii (Woloszynska) Seenaya and SubbaRaju isolated from a domestic water supply reservoir. Applied and Environmental Microbiology, v. 50, n. 5, p. 1292-1295, 1985. 
HIMBERG, K.; KEIJOLA, A. M.; HIISVIRTA, L.; PYYSALO, H.;SIVONEN, K. The effect of water treatment processes on the removal of hepatotoxins from Microcystisand Oscillatoriacyanobacteria: A laboratory study. Water Research, v.23, n.8, p.979984, 1989.

HRUDEY, S.; BURCH, M.; DRIKAS M.; GREGORY, R.Remedial measures. In Chorus, Bartraneditors.Toxic cyanobacteria in water: London: Spon Press, 1999.

HUMPAGE, A.R, FALCONER, I.R. Microcystin-LR and liver tumour promotion: effectson cytokinesis, ploidy, and apoptosis in cultured hepatocytes. Env.Toxicol. Water Qual., 14(1), In Press, 1999.

HO, L. et al. Chlorination of Four Microcystin Variants: MCLA is the most difficult microcystin variant to treat. Water-melbourne then artarmon, v. 33, n. 1, p. 65, 2006.

HO, L. et al.Optimising water treatment practices for the removal of Anabaena circinalis and its associated metabolites, geosmin and saxitoxins. Journal of water and health, v. 7, n. 4, p. 544-556, 2009.

HOFFMAN, J. R. H. Removal of Microcystis toxins in water purification process. WaterS. A., v. 2, p. 58-60, 1976.

JEON, B.S. et al. The removal of Microcystisichthyoblabe cells and its hepatotoxinmicrocystin-LR during electrooxidation process using Pt/Ti electrodes. Journal of Environmental Science and Health, Part A, v. 50, n. 6, p. 563-570, 2015.

JURCZAK, T. et al. Elimination of microcystins by water treatment processes examples from Sulejow Reservoir, Poland. Water research, v. 39, n. 11, p. 23942406, 2005.

JONES, G. J. Limnological study of cyanobacterial dominance in three South-East Queensland reservoirs. Managing Algal Blooms: Outcomes from the CSIRO BlueGreen Algal Research Program.CSIRO Land andWater, Canberra, Australia, p. 51-66, 1997.

LAWTON, L.; MARSALEK, B.; PADISÁK, J.; CHORUS, I.Determination of cyanobacteria in the laboratory.In Chorus, Bartran editors. Toxic cyanobacteria in water: London: Spon Press, 1999. 
LAWTON, L. A; ROBERTSON, P. K J. Physico-chemical treatment methods for the removal of microcystins (cyanobacterialhepatotoxins) from potable waters.Chemical Society Reviews, v. 28, n. 4, p. 217-224, 1999.

LIANG, W. et al. Electrochemical degradation of cyanobacterial toxin microcystin$\mathrm{LR}$ using $\mathrm{Ti} / \mathrm{RuO}_{2}$ electrodes in a continuous tubular reactor.Environmental Engineering Science, v. 25, n. 5, p. 635-642, 2008.

MACKINTOSH, C., et al.Cyanobacterialmicrocystin-LR is a potent and specific inhibitor of protein phosphatases 1 and 2A from both mammals and higher plants. Fed. Eur. Biochem. Soc. Lett., 264(2), 187-192, 1990.

MORAVCSIK, M. J. Measures of scientific growth. Research Policy, 2:266-75, 1973. p. 273-4. apud FERREZ, H.; Dodd. Análise da literatura periódica brasileira na área de História. Rio de Janeiro, UFRJ/ECO/IBICT, 1981. 168p.

NICHOLAS, D.; RITCHIE, M. Literature and bibliometrics. London: Clive Bingley, 1978.

NICHOLSON, B.; ROSITANO, J.; BURCH, M. Destruction of cyanobacterial peptide hepatotoxins by chlorine and chloramine.Water Res., v.28, p.I297-1303, 1994.

OHTANI, I., MOORE, R.E. e RUNNEGAR, M.T.C. Cylindrospermopsin, a potent hepatotoxin from the blue-green alga Cylindrospermopsisraciborskii. J. Amer. Chem. Soc., 114, 7941-7942, 1992.

PAERL, H.W.; HUISMAN, J. Blooms like it hot.Science - New York Then Washington, v. 320, n. 5872, p. 57, 2008.

PERA-TITUS, M. et al. Degradation of chlorophenols by means of advanced oxidation processes: a general review. Applied Catalysis B: Environmental, v. 47, n. 4, p. 219-256, 2004.

PRICE, D. J. de S. Society's need in scientific and technical information.Ciência da Informação, Rio de Janeiro, 3 (2): 97-103, 1974.

ROSITANO, J.; NICHOLSON, B.; PIERONNE, P. Destruction of cyanobacterial toxins byozone.Ozone Sei Eng., v.20, p.223-238, 1998. Pajek? Perspectivas em Ciência da Informação, v. 19, n. 3, p. 52-81, 2014. 
SIVONEN, K.; JONES, G. Cyanobacterialtoxins.InChorus,

Bartraneditors.Toxiccyanobacteria in water: London: Spon Press, 1999.

SIVONEN, K. Cyanobacterial toxins and toxin production. Phycologia, 35 (6 Supplement), 12-24, 1996.

SIVONEN, K. Effects of light, temperature, nitrate, orthophosphate, and bacteria on growth of and hepatotoxin production by Oscillatoriaagardhii strains. App. Environ. Microbiol., 56, 2658-2666, 1990.

TSUJI, Kiyomiet al. Stability of microcystins from cyanobacteria -IV.Effect of chlorination on decomposition. Toxicon, v. 35, n. 7, p. 1033-1041, 1997.

VILELA, W. F. D.et al.Degradation of [D-Leu]-Microcystin-LR by solar heterogeneous photocatalysis $\left(\mathrm{TiO}_{2}\right)$. Solar Energy, v. 86, n. 9, p. 2746-2752, 2012.

XAGORARAKI, I. et al. Inactivation kinetics of the cyanobacterial toxin microcystinLR by free chlorine.Journal of Environmental Engineering, v. 132, n. 7, p. 818-823, 2006.

ZIMAN, J. M. Information, communication, knowledge. Nature, 224: 318-24, 1969.

ZHANG, C.; FU, D.; GU, Z. Degradation of microcystin-RR using boron-doped diamond electrode.Journal of hazardous materials, v. 172, n. 2, p. 847-853, 2009.

Recebido: 03 abr. 2018.

Aprovado: 09 jun. 2018

DOI: $10.3895 /$ rbpd.v7n4.6867

Como citar: MULLER, L.; PAGIORO, T. A.; FREITAS, A. M.; PAGIORO, L. M. Cianobactérias, cianotoxinas

e o tratamento químico da água: uma análise bibliométrica da produção científica mundial. R. bras. Planej.

Desenv.,Curitiba, v. 7, n. 4, p. 570-596, set./dez. 2018.Disponível em: <https://periodicos.utfpr.edu.br/rbpd>

Acesso em: XXX.

Correspondência:

Luciana Muller

Av. Sete de Setembro, 3165 - Rebouças CEP 80230-901 - Curitiba - PR - Brasil

Direito autoral: Este artigo está licenciado sob os termos da Licença CreativeCommons-Atribuição 4.0

Internacional.

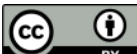

